\title{
Prescribing Pattern for Parkinson's Disease in Indian Community before Referral to Tertiary Center
}

\author{
Pratibha Surathi, Nitish Kamble, Ketaki Swapnil Bhalsing, Ravi Yadav, \\ Pramod Kumar Pal
}

\begin{abstract}
Background: Several factors determine the choice of medications in patients with Parkinson's disease (PD). We aimed to analyze the pattern of prescription of drugs in patients with PD before attending a tertiary-care center. Methods: The study included chart review of 800 PD patients attending the Department of Neurology of the National Institute of Mental Health and Neurosciences in Bangalore, India. Results: The mean age at onset was 51.1 \pm 11.8 years. The mean duration of illness was $41.7 \pm 43.6$ months. At first visit, $79.4 \%$ (group $1, n=635$ ) of patients were on medications, $10 \%$ (group $2, n=80$ ) were on medications but later discontinued, and $10.6 \%$ (group 3, $n=85$ ) were drug-naïve. Overall, levodopa was prescribed in 94.8\%, trihexyphenidyl in $40.4 \%$, dopamine agonists in $23.2 \%$, and amantadine in $17.2 \%$ either as monotherapy or in combination. In group $1,37.8 \%$ were on monotherapy, with levodopa being the most commonly used agent (33.1\%), followed by trihexyphenidyl (2.2\%), dopamine agonists $(1.6 \%)$, and amantadine $(0.6 \%)$. Among those on polytherapy, levodopa plus trihexyphenidyl was the preferred combination (23.9\%). In group 2, levodopa monotherapy was also most common (72.5\%), followed by trihexyphenidyl monotherapy (7.5\%). Conclusions: Levodopa and trihexyphenidyl were the most commonly prescribed drugs in our patients. A higher use of trihexyphenidyl could be due to its easy availability, low cost, and better tolerability in our patients, who were relatively young at the time of onset of their disease. The choice of antiparkinsonian medications at the primary and secondary care levels in India may be inappropriate, and newer guidelines tailored to the Indian context are warranted.
\end{abstract}

RÉSUMÉ: Tendances pharmacothérapeutiques en lien avec la maladie de Parkinson au sein d'une communauté indienne préalablement à l'aiguillage vers un centre de soins tertiaires. Contexte: Nombreux sont les facteurs qui président au choix de médicaments donnés à des patients atteints de la maladie de Parkinson. À cet égard, nous avons voulu analyser les tendances pharmacothérapeutiques au sein d'un groupe de patients avant qu'ils ne soient dirigés vers un centre de soins tertiaires. Méthodes: L'étude a inclus l'examen de 800 dossiers de patients ayant fréquenté le service de neurologie de l'Institut national de santé mentale et de neurosciences de la ville indienne de Bangalore. Résultats: L'âge moyen d'apparition de la maladie était de 51,1 $\pm 11,8$ ans ; sa durée moyenne, elle, était de 41,7 $\pm 43,6$ mois. Au moment de leur première visite, 79,4 \% des patients prenaient des médicaments (groupe 1, $n=635$ ); $10 \%$ d'entre eux en prenaient mais allaient ensuite cesser de le faire (groupe 2, $n=80$ ); enfin, 10,6\% n'avaient bénéficié d'aucun traitement de ce type (groupe 3, $n=85$ ). De façon générale, la lévodopa avait été prescrite chez $94,8 \%$ des patients ; le trihexyphénidyle, chez 40,4\% d'entre eux ; les agonistes de la dopamine, chez 23,2\% d'entre eux ; l'amantadine, chez 17,2\% d'entre eux que ce soit à titre de monothérapie ou combinée à un autre médicament. Au sein du groupe 1, 37,8\% des patients suivaient une monothérapie, la lévodopa étant le médicament le plus couramment utilisé $(33,1 \%)$; suivaient ensuite le trihexyphénidyle $(2,2 \%)$, les agonistes de la dopamine $(1,6 \%)$ et l'amantadine $(0,6 \%)$. Parmi les patients suivant une polythérapie, la combinaison entre la lévodopa et le trihexyphénidyle était la plus courante (23,9\%). Dans le groupe 2, la monothérapie à base de lévodopa était aussi la plus répandue $(72,5 \%)$, devançant nettement celle à base de trihexyphénidyle (7,5\%). Conclusions: La lévodopa et le trihexyphénidyle se sont révélés les deux médicaments les plus couramment prescrits chez nos patients. Une plus grande utilisation du trihexyphénidyle pourrait être attribuée à un accès plus facile, à un coût plus abordable et à une meilleure tolérabilité chez nos patients, lesquels étaient particulièrement jeunes au moment de l'apparition de leur maladie. Le fait d'opter pour des médicaments antiparkinsoniens dans des centres de soins primaires et secondaires pourrait en outre se révéler inapproprié en Inde. Enfin, de nouvelles lignes directrices, adaptées au contexte indien, nous semblent nécessaires.

Keywords: Treatment, Parkinson's disease, levodopa, levodopa equivalent daily dose, LEDD, dopamine agonists, anticholinergics doi:10.1017/cjn.2017.208

Can J Neurol Sci. 2017; 44: 705-710

From the Department of Neurology, National Institute of Mental Health and Neurosciences, Bangalore, India (PS, NK, KSB, RY, PKP).

Received September 9, 2016. Final Revisions Submitted April 22, 2017. Date of Acceptance April 28, 2017.

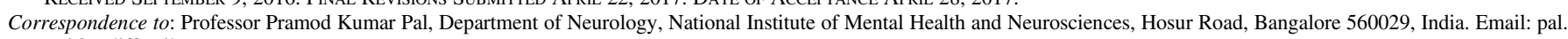
pramod@rediffmail.com 


\section{INTRODUCTION}

Parkinson's disease (PD) is the second most common neurodegenerative disorder. ${ }^{1}$ The prevalence of PD in industrialized countries has been estimated to be around $0.3 \%$ in the entire population and $3 \%$ in patients above 65 years of age. ${ }^{2,3}$ This disease tends to have a significant social and financial burden. Following the discovery of levodopa (LD) in the 1960s, it has remained the most widely used drug for the treatment of PD. ${ }^{4}$ Several other treatment options have become available, both medical and surgical, but pharmacotherapy remains the mainstay of treatment.

Several factors determine the choice of medications in patients with PD. The general principle of therapy is to keep the patient functionally independent for as long as possible..$^{5}$ The drugs employed depend on the age of the patient, the stage of the disease, affordability, the presence of motor fluctuations, and coexisting other neurological, psychiatric, and systemic disorders. Patients respond favorably to treatment in the early stage of disease. However, once the motor fluctuations and nonmotor symptoms become prominent, treatment needs to be individualized, with regular monitoring of efficacy and side effects. ${ }^{6}$ It is also necessary to identify patients who may benefit from deep brain stimulation.

About $70 \%$ of the Indian population live in rural areas and have limited access to a movement-disorder specialist. ${ }^{7}$ General physicians or internists treat the majority of these patients. ${ }^{8}$ The prescription pattern differs widely for several reasons: the experience of the treating physician, the cost of therapy, drug compliance, an awareness of the disease in the community, the patient's education and understanding of the disease, a lack of medical insurance for most patients, and easy availability of indigenous and alternative therapies. ${ }^{9,10}$ Moreover, as our patients are free to consult any doctor, the prescription pattern also varies depending on the number of doctors consulted.

There is a need to assess the appropriateness and adequacy of the treatment of Parkinson's disease in the community. We therefore undertook this study to review the pattern of medication prescription in the community prior to attending our tertiary-care center.

\section{MethodS}

Our study was a chart review of 800 patients with PD attending for the first time the Department of Neurology of the National Institute of Mental Health and Neurosciences in Bangalore, India, which is a tertiary-care referral neurosciences center. The institutional ethics committee of the institute approved the study. PD patients presenting during the years 2001-2014 were included. The senior movement-disorder specialist (PKP) examined all the patients in detail. The diagnosis of PD was based on Calne's criteria. ${ }^{11}$

The demographic profile, referral diagnosis, and clinical details (including age at onset, duration of illness, and Hoehn and Yahr $[\mathrm{H} \& \mathrm{Y}]$ staging) were retrieved from the case records. A detailed history of all the medications used by the patients, including the dosage and duration of each drug, was recorded. Patients were subdivided into three groups: (1) group 1-patients who were on medications at the time of their first visit; (2) group 2-patients who initially received medications but later discontinued; and (3) group 3-patients who never took any medications for PD (drug-naïve). In all the groups, patients were subgrouped into tremor-predominant and akinetic-rigid PD. ${ }^{12,13}$

The levodopa equivalent daily dosage (LEDD) was calculated for group 1 and 2 patients. These calculations were based on the standardized formulae proposed by Tomlinson et al. ${ }^{14}$ The conversion factors used were: $\times 1$ for immediate-release $\mathrm{LD}, \times 0.75$ for controlledrelease LD, $\times 0.33$ for entacapone, $\times 100$ for pramipexole, $\times 20$ for ropinirole, $\times 10$ for selegiline, $\times 100$ for rasagiline, and $\times 1$ for amantadine. The total LEDD (T-LEDD) was calculated by adding all dopaminergic medications including LD and a dopamine agonist (DA), while levodopa-LEDD (LD-LEDD) was calculated by adding only LD doses (both immediate-release and controlled-release).

The demographic and disease characteristics of the patients within the groups were compared using a one-way ANOVA test and post-hoc Bonferroni analysis (with a value of $p<0.05$ considered significant). The mean LEDD according to subtype of PD and presence of dyskinesia was calculated using the chi-square test. Pearson's correlation was employed to analyze the relationship between T-LEDD and H\&Y staging, duration of the disease, and the patient's income.

\section{RESUltS \\ Demographics and General Characteristics (Table 1)}

A total of 800 patients $(23.8 \%$ women) were included in the study. The mean age of PD patients was $54.9 \pm 11.3$ years, and the age at onset of motor symptoms was $51.1 \pm 11.8$ years. The duration of motor symptoms at the time of their first visit to our center ranged from 1 month to 20 years, with a mean of $41.7 \pm 43.6$ months ( $3.5 \pm 3.7$ years). Approximately $42 \%$ patients were from rural areas. The average monthly income of the whole group was Rs $4903.5 \pm 5053.3$ (USD $75.7 \pm 78.01$ ). Approximately $84.5 \%$ had a monthly income of less than Rs 10,000 ( USD 154.4).

The initial diagnosis was made by general practitioners (with only an MBBS degree) in $29.1 \%$, by internists (with an MD in medicine) in $53.8 \%$, and by neurologists (a DM or DNB in neurology) in $16.8 \%$ of patients. Nearly three-quarters of patients $(74.3 \%)$ consulted us for a second opinion regarding the diagnosis and treatment, and the rest were referred for better care.

The mean age at onset of motor symptoms in group 1 patients was $51.1 \pm 11.6$ years, $52 \pm 13.1$ years in group 2 , and $50.4 \pm 12.5$ years in group 3, the differences being statistically insignificant between groups. Men outnumbered women in all groups. The majority of patients in group 3 were from rural areas as compared to the other two groups. The duration of illness in groups 2 (28.7 \pm 25.4 months) and $3(17.1 \pm 13.7$ months) was shorter than in group 1 $(46.6 \pm 46.5$ months), which was statistically significant $(p=0.001)$.

In the majority of patients $(58.7 \%)$, the initial symptoms were noted on the left side. About $59.9 \%$ patients had tremorpredominant PD. Among the subgroups, group 1 (61.7\%) and group $3(58.9 \%)$ had tremor-predominant PD, whereas akinetic rigid-predominant $\mathrm{PD}$ was more common $(53.8 \%)$ in group 2 . The difference was significant between groups 1 and $2(p<0.001)$ and between groups 2 and $3(p<0.01)$. There was no significant difference in H\&Y stage among the three groups. The details are presented in Table 1.

\section{Medications Used at the First Visit}

At the first visit, $79.4 \%$ (group 1, $n=635$ ) of the patients were on medications for PD, $10 \%$ (group 2, $n=80$ ) of patients were on medications earlier but had discontinued, and $10.6 \%$ (group 3, $n=85$ ) were not on any antiparkinsonian drugs. The exact reasons for discontinuation of medications were not known in most of 
Table 1: General characteristics of the patients

\begin{tabular}{|c|c|c|c|c|c|c|c|}
\hline & Whole sample & Group 1 & Group 2 & Group 3 & Groups & Groups & Groups \\
\hline Characteristic & $(N=800)$ & $(n=635)$ & $(n=80)$ & $(n=85)$ & 1 vs. $2^{*}$ & 1 vs. $3^{*}$ & 2 vs. $3^{*}$ \\
\hline Age, years & $54.9 \pm 11.3$ & $55.1 \pm 11$ & $54.4 \pm 12.9$ & $53.6 \pm 11.9$ & 1.0 & 0.75 & 1.0 \\
\hline Age at onset, years & $51.1 \pm 11.8$ & $51.1 \pm 11.6$ & $52 \pm 13.1$ & $50.4 \pm 12.5$ & 1.0 & 1.0 & 1.0 \\
\hline Women, $n(\%)$ & $190(23.8 \%)$ & $137(21.6 \%)$ & $24(30 \%)$ & $29(34.1 \%)$ & 0.09 & 0.01 & 0.57 \\
\hline Duration of illness, months & $41.7 \pm 43.6$ & $46.6 \pm 46.5$ & $28.7 \pm 25.4$ & $17.1 \pm 13.7$ & 0.001 & $<0.001$ & 0.24 \\
\hline Income, Rs & $4903.5 \pm 5053.3$ & $5095.7 \pm 5246.6$ & $3645 \pm 4098.9$ & $4651.7 \pm 4181.4$ & 0.04 & 1.0 & 0.6 \\
\hline Rural, $n(\%)$ & $336(42 \%)$ & $248(39.1 \%)$ & $39(48.7 \%)$ & $49(57.6 \%)$ & 0.25 & 0.005 & 0.51 \\
\hline Side affected first (left), $n(\%)$ & $470(58.7 \%)$ & $379(59.7 \%)$ & $47(58.7 \%)$ & $44(51.7 \%)$ & 0.9 & 0.1 & 0.25 \\
\hline PD subtype (tremor-predominant), $n(\%)$ & $479(59.9 \%)$ & $392(61.7 \%)$ & $37(46.2 \%)$ & $50(58.9 \%)$ & $<0.001$ & 0.42 & 0.01 \\
\hline H\&Y stage, $n \pm S D$ & $2.1 \pm 0.7$ & $2.1 \pm 0.6$ & $2 \pm 0.7$ & $2 \pm 0.7$ & 1.0 & 0.4 & 1.0 \\
\hline Total LEDD, $n \pm S D$ & $448.1 \pm 304.5$ & $469.5 \pm 308.9$ & $281.5 \pm 201.8$ & - & $<0.001$ & - & - \\
\hline History of dyskinesia, $n(\%)$ & $137(17.1 \%)$ & $129(20.3 \%)$ & $8(10 \%)$ & - & 0.02 & - & - \\
\hline
\end{tabular}

*Indicates $p$ value (ANOVA with Bonferroni post-hoc analysis).

LEDD $=$ levodopa equivalent daily dose; $S D=$ standard deviation.

these patients, but in $44 \%$ the reasons for the visit to our hospital were either dissatisfaction with treatment or to obtain a second opinion about their illness.

A comparison of the patients in group 1 with those in group 2 (Table 1) showed that patients who discontinued medications (group 2) had a shorter duration of illness, lower socioeconomic status, and lesser incidence of a tremor-predominant phenotype of PD compared to those who continued medications (group 1). The various medications used by the patients at the time of the first consultation at our hospital are presented in Table 2.

LD was the most common medication prescribed in groups 1 $(93.1 \%)$ and $2(85 \%)$, either as monotherapy or in combination with other drugs. About $43.1 \%$ in group 1 were on two medications, $37.8 \%$ on monotherapy, and $\sim 19.1 \%$ on three or more medications. LD monotherapy was most common $(33.1 \%)$, followed by trihexyphenidyl (THP) (2.2\%), DAs (1.6\%), and amantadine $(0.6 \%)$. Among the DAs, the ergot-derived piribedil was prescribed in $0.3 \%$ of patients. In those receiving polytherapy (62.2\%), several drug combinations were employed (see Table 2), with LD plus THP being the most commonly used combination $(23.9 \%)$. Other medications that were prescribed in a few of the PD patients were propranolol and clonazepam.

In group 2, LD monotherapy was also most common (72.5\%), followed by THP monotherapy $(7.5 \%)$ and the combination of LD plus THP (6.3\%). Patients in this group were never prescribed three or more antiparkinsonian medications.

Further analysis to determine the frequency of individual drug prescriptions either as monotherapy or in combination with other drugs showed that THP was the next most commonly used drug after LD. The details are given in Table 3.

A history of dyskinesia was more frequent in group $1(20.3 \%)$ than in group $2(10 \%)$, a difference that was statistically significant $(p=0.02)$.

\section{Analysis of LEDD Doses}

The mean daily T-LEDD was $448.1 \pm 304.5 \mathrm{mg}$ for the whole group, $469.5 \pm 308.9 \mathrm{mg}$ for group 1 , and $281.5 \pm 201.8 \mathrm{mg}$ for group 2. The T-LEDD difference between groups 1 and 2 was significant $(p \leq 0.001)$. Similarly, the LD-LEDD for the whole group was $378.1 \pm 369.0 \mathrm{mg}, 379.9 \pm 362.1 \mathrm{mg}$ for group 1 , and $376.3 \pm 106.1 \mathrm{mg}$ for group 2 . In group 1, patients with a history of dyskinesia $(n=129)$ were on a higher T-LEDD compared to those without $(n=506 ; 564.25 \pm 327.67 \mathrm{mg}$ vs. $445.34 \pm$ $299.56 \mathrm{mg} ; p<0.001)$.

\section{DISCUSSION}

This study analyzed a cohort of 800 PD patients with different medication prescriptions before their first consultation with a movement-disorder specialist in a tertiary-care center in India. In comparison to other studies, the age at onset of our cohort was less by 10 to 20 years. ${ }^{3,15-18}$ General practitioners and internists diagnosed most of the patients (82.9\%) initially. Around $20.6 \%$ of patients (groups 2 and 3) were not on medications at the time of first attending our hospital. The factors more often associated with discontinuation of medications were probably shorter duration of illness, low socioeconomic status, and akinetic rigid phenotype. Poor medication compliance in PD has been reported to be around $15-67 \%{ }^{19}$ This included skipping doses, taking lesser doses than prescribed, and taking medications at the wrong time of day. The reasons that have been attributed include depression, cognitive impairment, lack of social support, poor health education, the cost of medications, and patients' unrealistic expectations about the beneficial effects of the medications. ${ }^{19-21}$

The most commonly prescribed medications in our study were LD alone $(37.5 \%)$, followed by LD in combination with THP $(21.9 \%)$ or with a DA $(8.2 \%)$. This is in sharp contrast to the higher prevalence of a combination of LD plus a DA reported from other countries - such as Korea (61.2\%), Japan (56\%), Italy $(41.3 \%)$, Europe (40\%), and the United States (35\%). ${ }^{22-24}$ Most of the patients in group 1 were on LD, either monotherapy or in combination with other drugs. A few patients (3.6\%) were not on any dopaminergic drugs but were on such other drugs as anticholinergics and beta blockers only. 


\section{Table 2: Profile of medications used by the patients}

\begin{tabular}{|c|c|c|c|}
\hline & Group 1+2 & Group 1 & Group 2 \\
\hline Medications & $(n=715)$ & $(n=635)$ & $(n=80)$ \\
\hline Monotherapy & $308(43.1 \%)$ & $240(37.8 \%)$ & $68(85 \%)$ \\
\hline LD & $268(37.5 \%)$ & $210(33.1 \%)$ & $58(72.5 \%)$ \\
\hline THP & $20(2.8 \% \%)$ & $14(2.2 \%)$ & $6(7.5 \%)$ \\
\hline DAs & $12(1.7 \%)$ & $10(1.6 \%)$ & $2(2.5 \%)$ \\
\hline Amantadine & $4(0.5 \%)$ & $4(0.6 \%)$ & 0 \\
\hline COMTi & $2(0.3 \%)$ & 0 & $2(2.5 \%)$ \\
\hline MAO-Bi & $2(0.3 \%)$ & $2(0.3 \%)$ & 0 \\
\hline Two-drug therapy & $286(40 \%)$ & $274(43.1 \%)$ & $12(15 \%)$ \\
\hline $\mathrm{LD}+\mathrm{THP}$ & $157(21.9 \%)$ & $152(23.9 \%)$ & $5(6.3 \%)$ \\
\hline $\mathrm{LD}+\mathrm{DA}$ & $59(8.2 \%)$ & $56(8.8 \%)$ & $3(3.8 \%)$ \\
\hline LD + amantadine & $42(5.9 \%)$ & $41(6.5 \%)$ & $1(1.3 \%)$ \\
\hline $\mathrm{LD}+\mathrm{COMTi}$ & $11(1.5 \%)$ & $10(1.6 \%)$ & $1(1.3 \%)$ \\
\hline $\mathrm{LD}+\mathrm{MAO}-\mathrm{Bi}$ & $8(1.1 \%)$ & $8(1.3 \%)$ & 0 \\
\hline $\mathrm{DA}+\mathrm{MAO}-\mathrm{Bi}$ & $3(0.4 \%)$ & $3(0.5 \%)$ & 0 \\
\hline $\mathrm{DA}+\mathrm{THP}$ & $2(0.3 \%)$ & 0 & $2(2.5 \%)$ \\
\hline DA + amantadine & $1(0.1 \%)$ & $1(0.16 \%)$ & 0 \\
\hline Amantadine + MAO-Bi & $1(0.1 \%)$ & $1(0.16 \%)$ & 0 \\
\hline $\mathrm{THP}+\mathrm{MAO}-\mathrm{Bi}$ & $1(0.1 \%)$ & $1(0.16 \%)$ & 0 \\
\hline THP + amantadine & $1(0.1 \%)$ & $1(0.16 \%)$ & 0 \\
\hline Three or more drugs & $121(16.9 \%)$ & $121(19.1 \%)$ & 0 \\
\hline $\mathrm{LD}+\mathrm{DA}+\mathrm{THP}$ & $38(5.3 \%)$ & $38(5.9 \%)$ & 0 \\
\hline $\mathrm{LD}+\mathrm{THP}+$ amantadine & $23(3.2 \%)$ & $23(3.6 \%)$ & 0 \\
\hline $\mathrm{LD}+\mathrm{DA}+\mathrm{THP}+$ amantadine & $21(2.9 \%)$ & $21(3.3 \%)$ & 0 \\
\hline $\mathrm{LD}+\mathrm{DA}+$ amantadine & $16(2.2 \%)$ & $16(2.5 \%)$ & 0 \\
\hline $\mathrm{DA}+\mathrm{THP}+$ amantadine & $6(0.8 \%)$ & $6(0.9 \%)$ & 0 \\
\hline $\mathrm{LD}+\mathrm{COMTi}+\mathrm{MAO}-\mathrm{Bi}$ & $3(0.4 \%)$ & $3(0.5 \%)$ & 0 \\
\hline $\mathrm{LD}+$ amantadine + COMTi & $2(0.3 \%)$ & $2(0.3 \%)$ & 0 \\
\hline $\mathrm{LD}+\mathrm{DA}+\mathrm{COMTi}$ & $2(0.3 \%)$ & $2(0.3 \%)$ & 0 \\
\hline $\mathrm{LD}+\mathrm{THP}+\mathrm{COMTi}$ & $2(0.3 \%)$ & $2(0.3 \%)$ & 0 \\
\hline $\mathrm{LD}+\mathrm{THP}+\mathrm{MAO}-\mathrm{Bi}$ & $2(0.3 \%)$ & $2(0.3 \%)$ & 0 \\
\hline $\mathrm{LD}+\mathrm{DA}+\mathrm{MAO}-\mathrm{Bi}$ & $2(0.3 \%)$ & $2(0.3 \%)$ & 0 \\
\hline $\mathrm{DA}+\mathrm{THP}+\mathrm{MAO}-\mathrm{Bi}$ & $1(0.1 \%)$ & $1(0.1 \%)$ & 0 \\
\hline $\mathrm{LD}+\mathrm{THP}+\mathrm{COMTi}+\mathrm{MAO}-\mathrm{Bi}$ & $1(0.1 \%)$ & $1(0.16 \%)$ & 0 \\
\hline $\mathrm{LD}+\mathrm{DA}+$ amantadine $+\mathrm{MAO}-\mathrm{Bi}$ & $1(0.1 \%)$ & $1(0.16 \%)$ & 0 \\
\hline $\mathrm{LD}+\mathrm{THP}+$ amantadine $+\mathrm{COMTi}$ & $1(0.1 \%)$ & $1(0.1 \%)$ & 0 \\
\hline
\end{tabular}

COMTi $=$ catechol-O-methyl transferase inhibitor; DA = dopamine agonist; $\mathrm{LD}=$ levodopa; $\mathrm{MAO}-\mathrm{Bi}=$ monoamine oxidase $\mathrm{B}$ inhibitor; $\mathrm{THP}=$ trihexyphenidyl.

LD and THP were more often prescribed in India than DAs, which can be attributed to the increased cost of DAs, physicians' lack of experience with DAs, or an awareness of the potential side effects of DAs (including nausea, vomiting, peripheral edema, hallucinations, delusions, orthostatic hypotension, and compulsive behavior). ${ }^{25}$ In our study, THP was prescribed in all age groups equally, and it was the most common medication prescribed either alone or in combination (38.6\%) after LD alone
Table 3: Frequency of prescription of individual drugs in Parkinson's disease

\begin{tabular}{l|c|c|c}
\hline & Group 1+2 & Group 1 & Group 2 \\
\hline Medications & $(\boldsymbol{n}=\mathbf{7 1 5})$ & $(\boldsymbol{n}=\mathbf{6 3 5})$ & $(\boldsymbol{n}=\mathbf{8 0})$ \\
\hline $\mathrm{LD} \pm$ other medications & $659(92.2 \%)$ & $591(93.1 \%)$ & $68(85 \%)$ \\
\hline $\mathrm{THP} \pm$ other medications & $276(38.6 \%)$ & $263(41.4 \%)$ & $13(16.25 \%)$ \\
\hline $\mathrm{DA} \pm$ other medications & $164(22.9 \%)$ & $157(24.7 \%)$ & $7(8.7 \%)$ \\
\hline Amantadine \pm other medications & $119(16.6 \%)$ & $118(18.6 \%)$ & $1(1.2 \%)$ \\
\hline $\mathrm{MAO}-\mathrm{Bi} \pm$ other medications & $24(3.3 \%)$ & $24(3.8 \%)$ & 0 \\
\hline $\mathrm{COMTi} \pm$ other medications & $24(3.3 \%)$ & $21(3.3 \%)$ & $3(3.7 \%)$ \\
\hline
\end{tabular}

$\mathrm{COMTi}=$ catechol-O-methyl transferase inhibitor; $\mathrm{DA}=$ dopamine agonist; $\mathrm{LD}=$ levodopa; $\mathrm{MAO}-\mathrm{Bi}=$ monoamine oxidase $\mathrm{B}$ inhibitor; $\mathrm{THP}=$ trihexyphenidyl.

or in combination (92.2\%). In addition, our study cohort was relatively younger (mean age of onset $=54.9 \pm 11.3$ years) than the PD patients in other countries, where the mean age of PD onset is much higher (65 years). ${ }^{16-18}$ It is also possible that most of our patients had tremor-predominant PD, which might have led to an increased number of prescriptions for THP. Ideally, THP needs to be avoided in the elderly, as it may precipitate cognitive dysfunction and can affect bladder function in older males. A U.S. study ${ }^{25}$ found that the choice of initial therapy was determined by age, source of medical insurance, and comorbidities.

DAs alone or in combination with other drugs were prescribed in $22.9 \%$ of our 800 patients, which is much lower than that reported from other countries: Italy $(42.3 \%)$, Germany $(65 \%)$, Korea $(68.1 \%)$, and Japan $(71 \%) .22-24,26$ In our study, those who discontinued medications had been prescribed DA monotherapy more often than those who continued treatment ( 2.5 vs. $1.6 \%$, $p=0.01$ ). However, this was not observed when a DA was used along with other antiparkinsonian medications.

DA monotherapy was prescribed in $26.8 \%$ of PD patients in Singapore, and the preferred drug combination was LD plus benzhexol $(13.7 \%) .{ }^{27}$ In a study from southern Italy, ${ }^{28} \mathrm{LD}$ and anticholinergics were the most commonly prescribed medications. ${ }^{28}$ Anticholinergic monotherapy was used in $20.7 \%$, ergot-derived DAs in $19.4 \%$, LD in $14.8 \%$, and non-ergot DAs in $6.5 \%$. However, LD and other drug combinations were the most commonly prescribed medications in their patients. In our study, ergot-derived DAs (piribedil) were used only in $0.3 \%$ of patients. Piribedil is an expensive drug, and the lack of experience with this drug among our physicians and general practitioners may contribute to its reduced prescription rate. The side effects related to piribedil (an ergot alkaloid) and easy availability of other medications has also resulted in less use of this agent. In one study, ${ }^{21}$ maximum compliance was obtained with rasagiline.

Long-term affordability of medications in our patients is also an important factor, as most of them are not covered by medical insurance. Moreover, some patients may have preferred to take traditional forms of treatment, which are common for chronic diseases in our country. Finally, it is likely that our patients were not communicated with adequately about the nature of their illness, the need for drug compliance, the expected complications, and the importance of regular follow-ups. 
The use of catechol-O-methyl transferase (COMT) and monoamine oxidase $\mathrm{B}$ (MAO-B) inhibitors were also very low in our study.

To determine the effects of different dopaminergic medications, we also calculated T-LEDD and LD-LEDD for all of our patients. The LEDD usually correlates with patient gender and age. We found a decrease in LEDD in women and older patients. ${ }^{22}$ However, we did not find any effect of age and gender on LEDD.

Our patients who developed levodopa-induced dyskinesia (LID) were found to have a higher T-LEDD and LD-LEDD. Other studies have also found a higher LEDD in patients with LID compared to those without. ${ }^{29}$ The most common strategy to alleviate LID is to fractionate the LD dose. Other strategies include decreasing the LD dose and adding a DA with amantadine. ${ }^{30}$ Other important factors that determine LEDD are the stage and duration of the disease. ${ }^{16}$ Neither of these had any significant effect on LEDD in our patients. This suggests that adequate adjustment of medications according to the progression of the disease is lacking.

The strength of our study is that all the patients were evaluated by a single investigator, ensuring correct diagnosis of patients. The medication history was verified directly from the patients on their first visit to our hospital from their previous prescriptions and the medications they carried with them.

\section{LiMITATIONS}

One limitation of our study is that we did not assess the comorbidities of patients and the medications prescribed for other symptoms (including nonmotor symptoms) and other disorders, as these are very important factors in considering the type of treatment in PD patients. There may also be a small selection bias, as we reviewed only a fraction of the patients who attended our center.

\section{CONCLUSIONS}

The treatment of PD in our community, with most patients belonging to low and middle socioeconomic strata, may be inadequate in terms of using appropriate medications and adequate doses tailored to patients' needs. Anticholinergic drugs are more often used, even in the elderly. Such other recommended medications as DAs as well as MAO-B and COMT inhibitors are infrequently prescribed, probably because of higher costs, the side-effect profile, and the need for long-term treatment. Many of our patients were also drug-naïve, and there was a high rate of discontinuation of medications.

The pattern of prescription in PD patients reported in our study cannot be generalized, and our practices may not be applicable to affluent PD patients. However, as most of our patients were of low socioeconomic status, the data presented here may truly reflect the prevalent prescription pattern in our country. Therefore, this trend of treatment may represent what is occurring in 70 to $80 \%$ of the Indian population.

The awareness among general practitioners and internists regarding the characteristics of the disease, the course of the illness, the available treatment options, and the associated longterm side effects that come with these medications needs to be increased. This would encourage them to treat patients confidently with adequate dosages, to use all the available pharmacological treatments appropriately, and to more diligently ensure drug compliance. They also need to be aware of the appropriate timepoint at which patients need to be referred to a tertiary-care center or to a movement-disorder specialist.

\section{Disclosures}

Pratibha Surathi, Nitish Kamble, Ketaki Swapnil Bhalsing, Ravi Yadav, and Pramod Kumar Pal do not have anything to disclose. None of the authors have any financial disclosure to make or have any conflicts of interest.

\section{REFERENCES}

1. Tanner CM, Goldman SM. Epidemiology of Parkinson's disease. Neurol Clin. 1996;14(2):317-35.

2. Rajput AH. Epidemiology of Parkinson's disease. Can J Neurol Sci. 1984;11(Suppl 1):156-9.

3. Gourie-Devi M, Gururaj G, Satishchandra P, Subbakrishna DK. Prevalence of neurological disorders in Bangalore, India: a community-based study with a comparison between urban and rural areas. Neuroepidemiology. 2004;23(6):261-8.

4. Hornykiewicz O. A brief history of levodopa. J Neurol. 2010; 257(Suppl 2):S249-52.

5. Olanow CW, Stern MB, Sethi K. The scientific and clinical basis for the treatment of Parkinson disease (2009). Neurology. 2009; 72(21 Suppl 4):S1-136.

6. Surathi P, Jhunjhunwala K, Yadav R, Pal PK. Research in Parkinson's disease in India: a review. Ann Indian Acad Neurol. 2016; 9(1):9-20.

7. Bagcchi B. India has low doctor to patient ratio, study finds. BMJ. 2015;351:h5195.

8. Deo MG. Doctor population ratio for India: the reality. Indian J Med Res. 2013;137(4):632-5.

9. Bauer M, Monz BU, Montejo AL, et al. Prescribing patterns of antidepressants in Europe: results from the Factors Influencing Depression Endpoints Research (FINDER) study. Eur Psychiatry. 2008;23(1):66-73.

10. Tripathi A, Avasthi A, Desousa A, et al. Prescription pattern of antidepressants in five tertiary care psychiatric centres of India. Indian J Med Res. 2016;143(4):507-13.

11. Calne DB, Snow BJ, Lee C. Criteria for diagnosing Parkinson's disease. Ann Neurol. 1992;32(Suppl 1):S125-7.

12. Barbeau A, Porcher E. New data on the genetics of Parkinson's disease. Can J Neurol Sci. 1992;9(1):53-60.

13. Jankovic J, McDermott M, Carter J, et al. Variable expression of Parkinson's disease: a baseline analysis of the DATATOP cohort. Neurology. 1999;40:1529-34.

14. Tomlinson CL, Stowe R, Patel S, Rick C, Gray R, Clarke CE. Systematic review of levodopa dose equivalency reporting in Parkinson's disease. Mov Disord. 2010;25(15):2649-53.

15. Das SK, Biswas A, Roy $\mathrm{T}$, et al. A random sample survey for prevalence of major neurological disorders in Kolkata. Indian J Med Res. 2006;124(2):163-72.

16. Hoehn MM, Yahr MD. Parkinsonism: onset, progression and mortality. Neurology. 1967;17(5):427-42.

17. Van Den Eeden SK, Tanner CM, Bernstein AL, et al. Incidence of Parkinson's disease: variation by age, gender, and race/ethnicity. Am J Epidemiol. 2003;157(11):1015-22.

18. de Lau LM, Breteler MM. Epidemiology of Parkinson's disease. Lancet Neurol. 2006;5(6):525-35.

19. Fleisher JE, Stern MB. Medication nonadherence in Parkinson's disease. Curr Neurol Neurosci Rep. 2013;13(10):382.

20. Kulkarni AS, Balkrishnan R, Anderson RT, Edin HM, Kirsch J, Stacy MA. Medication adherence and associated outcomes in Medicare health maintenance organization-enrolled older adults with Parkinson's disease. Mov Disord. 2008; 23(3):359-65.

21. Tarrants ML, Denarie MF, Castelli-Haley J, Millard J, Zhang D. Drug therapies for Parkinson's disease: a database analysis of patient compliance and persistence. Am J Geriatr Pharmacother. 2010;8(4):374-83. 
22. Lee JY, Kim JW, Lee WY, et al. Daily dose of dopaminergic medications in Parkinson disease: clinical correlates and a posteriori equation. Neurol. Asia. 2010;15(2):137-43.

23. Woitalla D, Mueller T, Russ H, Hock K, Haeger DA. The management approaches to dyskinesia vary from country to country. Neuroepidemiology. 2007;29(3-4):163-9.

24. Leoni O, Martignoni E, Cosentino M, et al. Drug prescribing patterns in Parkinson's disease: a pharmacoepidemiological survey in a cohort of ambulatory patients. Pharmacoepidemiol Drug Saf. 2002;11(2):149-57.

25. Huse DM, Castelli-Haley J, Orsini LS, Lenhart G, Abdalla JA. Patterns of initial pharmacotherapy for Parkinson's disease in the United States. J Geriatr Psychiatry Neurol. 2006;19(2):91-7.

26. Schroder S, Kuessner D, Arnold G, Zollner Y, Jones E, Schaefer M. Do neurologists in Germany adhere to the national Parkinson's disease guideline? Neuropsychiatr Dis Treat. 2011;7:103-10.
27. Tan EK, Yeo AP, Tan V, Pavanni R, Wong MC. Prescribing pattern in Parkinson's disease: are cost and efficacy overriding factors? Int J Clin Pract. 2005;59(5):511-4.

28. Trifiro G, Savica R, Morgante L, et al. Prescribing pattern of anti-Parkinson drugs in Southern Italy: cross-sectional analysis in the years 2003-2005. Parkinsonism Relat Disord. 2008;14(5): 420-5.

29. Suh DC, Pahwa R, Mallya U. Treatment patterns and associated costs with Parkinson's disease levodopa induced dyskinesia. J Neurol Sci. 2012;319(1-2):24-31.

30. Muller T, Woitalla D, Russ H, Hock K, Haeger DA. Prevalence and treatment strategies of dyskinesia in patients with Parkinson's disease. J Neural Transm (Vienna). 2007;114(8): 1023-6. 